\title{
Determining If Competition Level Matters in Developing Positive and Negative Youth Sportsmanship
}

\author{
Skye Gerald Arthur-Banning ${ }^{1}$, Mary Sara Wells ${ }^{2}$, Brian Malcarne ${ }^{3}$, Young Suk Oh ${ }^{1}$ \\ ${ }^{1}$ Department of Parks, Recreation and Tourism Management, Clemson University, Clemson, USA \\ ${ }^{2}$ Department of Parks, Recreation and Tourism, University of Utah, Salt Lake, USA \\ ${ }^{3}$ Recreation and Leisure Administration, York College of Pennsylvania, York, USA
}

Email address:

sarthur@clemson.edu (S.G. Arthur-Banning),mary.wells@hsc.utah.edu(M. S. Wells),bmalcarn@ycp.edu (B. Malcarne)

\section{To cite this article:}

Skye Gerald Arthur-Banning, Mary Sara Wells, Brian Malcarne, Young Suk Oh. Determining If Competition Level Matters in Developing Positive and Negative Youth Sportsmanship. American Journal of Sports Science. Vol. 6, No. 2, 2018, pp. 38-46. doi: $10.11648 /$ j.ajss.20180602.12

Received: February 1, 2018; Accepted: February 16, 2018; Published: March 24, 2018

\begin{abstract}
Millions of young athletes engage in youth sport every year at a variety of levels ranging from beginning instruction up through elite national competitions. Parents are frequently registering these youth in sport for a variety of benefits including the frequently mentioned purpose of "building character". Although a vague term, building character is often associated with the concept of moral behavior or sportsmanship. Youth sport professionals hoping to develop programs focused on the benefits of improving sportsmanship should understand how all aspects of their programs can either improve or hinder these types of behaviors. This requires a greater understanding of how the level of competition will contribute to both positive and negative sportsmanship behaviors. Therefore, the purpose of this study was to determine if differences in positive and negative sportsmanship behaviors exist at various levels of competitive youth sport experiences. To accomplish this, systematic observations occurred at two different soccer tournaments. The first tournament was designed for elite athletes in the Mountain West region of the US while the second tournament was more recreationally based and was located in the South East. A total of 62 games were observed of young athletes in the U-12 and U-14 age groups. Prior to observing these games, observers went through an extensive training to ensure that they could reach $80 \%$ agreement in their observations of both the positive and negative sportsmanship behaviors engaged in by the athletes, spectators, and coaches of each game. Results from this study suggest a lack of difference between the two competitive levels in terms of positive sportsmanship behavior, but a significant $(p<05)$ difference did exist between the elite athletes and recreational athletes in the number of negative sportsmanship behaviors demonstrated in a half game with the elite athletes engaging in nearly four times as many negative sportsmanship behaviors. Although some limitations do exist, youth sport professionals can use this information in a variety of ways. To begin, programs targeted at improving sportsmanship now know how to better target their efforts. This can be done through additional trainings for the programs serving elite athletes. Finally, it is important to note that programs at all levels were demonstrating many positive qualities. Consequently, it would behoove youth sport professionals to attempt to minimize the negative behaviors without eliminating the opportunities for athletes, coaches, and spectators to behave positively.
\end{abstract}

Keywords: Youth Sport, Sportsmanship, Competition

\section{Introduction}

Youth sport is a prevalent activity in society. Millions of young athletes engage in sport at a variety of levels including instructional leagues all the way up through elite regional and national competitions. Parents register their children as young as three for a variety of developmental reasons including learning physical and social skills and the desire to "build character". While sport can, in fact, provide significant benefits to youth when programs are run well, unfortunately it can have the opposite effect when programs are either run poorly or do not focus correctly on development. One of the areas of youth development where this is very apparent is in moral behavior. Sport provides the necessary elements to learn and engage in sportsmanship, 
however, this can be done in both a positive and negative manner. For youth sport professionals developing programs that maximize positive while minimizing negative sportsmanship behaviors among their young athletes, it is important to understand all the elements that come in to play and how they are related. Among these elements is the competitive environment present in sporting events. This article is aimed at more fully understanding such a potential connection. More specifically, this study seeks to determine the relationship between the level of competition and positive and negative youth sportsmanship. To build this understanding, it is first necessary to more fully comprehend the constructs of sport, youth development, sportsmanship, and competition.

\section{Literature Review}

\subsection{Sport and Youth Development}

It is generally accepted that taking part in sports provides a positive and healthy impact on youth development [1] [2] [3]. Structured youth activities can provide participants with a context for developmental growth experiences [4]. More specifically, youth sport participation is considered to have the potential to provide important health and development benefits across various domains such as physical, cognitive, socio-emotional, and adaptive functioning [5].

Sport participation is associated with contributions to both physical and psychological health for youth participants [6] [7]. The most obvious benefit of sport participation is related to the health benefits that tend to come naturally to young athletes as a result of the regular physical activity that often accompanies many sports [8] [9]. According to the Centers for Disease Control and Prevention [10] regular physical activity positively contributes to physical health including strengthening the musculoskeletal system, assisting with weight management, and reducing the risks of diabetes, high blood pressure, and heart disease. Properly facilitated youth sports are expected to produce health and fitness benefits for participants that exceed physical health gains derived from non-organized physical activity such as free play [9]. In addition, psychological benefits of regular physical exercise include the promotion of well-being and mood stability, while decreasing emotions associated with anxiety and depression [10].

Sport involvement may also contribute to the social and personal development of youth. It has also been proposed that youth sport provides benefits for socio-emotional development [6], identity work, character building [11] [4], and moral development, including the expression of values and sportsmanship behaviors [12] [13]. Many people involved in sport also believe that sport participation offers opportunities for learning and development that can directly transfer into other areas of life such as school and work [2].

One cannot assume, however, that sport participation will inherently have a positive impact on youth [8] [2]. Some youth sport experiences may not prove beneficial to participants, while other sport experiences may even create negative outcomes and result in unhealthy development [14] [6]. For example, even benefits inherent to physical activity are reported as being limited if programs do not provide appropriate and sufficient levels of activity to result in measureable gains in health and fitness [9]. Youth sport participation also needs to be safe so as to avoid negative experiences related to the occurrence of sport injuries [9]. The building of youth character that is often thought to take place through youth sport can also be challenged and negatively influenced through exposure to negative experiences in a competitive sport context [4].

\subsection{Youth Character Development and Sportsmanship}

The assumption that youth sports build character is ingrained in American culture [15] [6]. While sport participation is popularly accepted and promoted as contributing to youth character development, skepticism exists among some researchers [16]. For the most part, many believe that the link between youth sport and character development is anecdotal and lacking in scientific support [6]. Many earlier studies on character development in youth sport have been criticized as not being methodologically sound due to selection problems [15] [17]. Although methodological techniques have improved in recent years, current studies on character development through youth sport continue to be criticized because the definition of character is vague and various studies limit their focus to a selected aspect of character development such as aggression or moral reasoning [15].

Sport involvement has been linked to an array of potential benefits that may be associated with or contribute to character development which makes understanding contributions to youth character development even more difficult to pinpoint and measure [15]. Although the concept of character may best refer to personal attributes, some argue that character must also be linked to behavior to make its meaning useful [13]. Due to the vast notion of character development and the extensive list of potential contributing benefits to character, some suggest that researchers focus on learning outcomes and behaviors related to character that are a most natural fit for sport participation such as sportsmanship [15]. Character development has been considered by some to fit within the framework of moral development which takes into account attitudes and behaviors related to sportsmanship [18]. Thus, although only a small and contextual component of human character, understanding sportsmanship behaviors may provide valuable insight into youth character development and expression within the context of youth sport participation.

Many researchers have set the expectation that the development of positive moral character through youth sport occurs as a result of observation, practice, and learning prosocial behaviors related to sportsmanship [19]. In addition to expectations for positive character development in youth sport, others suggest that there is potential for unhealthy character development through observing, practicing, and 
learning negative behaviors related to poor sportsmanship [19]. Negative sportsmanship behaviors related to moral character include unsportsmanlike conduct and moral disengagement. For example, a competitive youth sport context with an extreme focus on winning may encourage players to engage in unsportsmanlike behaviors in order to gain a competitive advantage [12]. Further, athletes engaged in competitive sport have been found to use moral disengagement strategies of blaming and minimization to justify unsportsmanlike behaviors during play [20]. Youth participants who consistently engage in poor sportsmanship are essentially learning patterns of behaviors to perform and rationalize that may be inconsistent with healthy moral development and expressions of character.

\subsection{Sport Context and Youth Character Development}

Impact on character development and sportsmanship of youth involved in sport is thought to depend less on the actual sport itself and more on the context in which sport participation is experienced [8]. Factors that can potentially contribute to youth sportsmanship behaviors and aspects of character development include deliberately promoting desired program outcomes, establishing an appropriate motivational climate, considering the social climate and adult modeling of behaviors, and developing a better understanding of the role of competition in youth sport. As a result, such factors can occur in many different sports and coaches, peers, parents and administrators can all contribute to the context specificity of the environment.

If developing moral character is a desired outcome of youth sport, then it is the responsibility of all involved stakeholders, including sport organizations, officials, coaches, parents, and players to promote positive moral behavior and character development in youth sport [5]. Although negative experiences can potentially occur in any activity, some evidence suggests that due to the competitive nature of sport, youth are more likely to encounter negative experiences within that context than in other organized community-based or extra-curricular activities [4]. For example, the competitive component of sport has been linked to some of the unfavorable experiences reported by youth due to the occurrence of negative peer interactions related to poor sportsmanship and observation of inappropriate behaviors of coaches and parents [4] [21]. Adults involved in youth sport must actively integrate learning experiences into the sport experience in order to promote a context for healthy character development [22]. These learning experiences may, for example, promote positive relationships between players and involved adults, target learning objectives related to sport competencies, and address individual needs of the youth. If applied appropriately, competitive youth sport may be useful in providing youth with increases in self-esteem, sense of purpose, sense of responsibility, and experience with life lessons [5].

Even though youth sport participants may already have a disposition toward a specific goal orientation, coaches and administrators need to be aware of the motivational climate that their sport program fosters. Sport psychologists have identified that athletes have an achievement goal orientation, also referred to as a competitive orientation, that helps to explain game play behavior [19]. There are two achievement goal orientations toward competition that have been identified: task orientation and ego orientation [23]. Athletes with a mastery (or task) orientation are focused on personal skill development and mastery, playing well, and self evaluated performance [19]. Young athletes with intrinsic goal orientations such as skill development have been found to be more likely to engage in pro-social behaviors during competitive play than athletes with extrinsic goal orientations such as social status or rewards [24]. Athletes with an ego orientation are characterized as concerned about being seen as successful, winning at all costs, and dominating over the opposing team [18] [19]. Furthermore, some researchers suggest that sportsmanship becomes less of a focus when perceptions of ego orientation dominate [18].

Sport administrators and other involved adults need to deliberately cultivate a sport context and climate that facilitates potential benefits to youth character development rather than undermining it [2] [12]. By incorporating cooperation and a task orientation focus in youth sport, coaches and administrators can produce an environment designed to support youth development that is more likely to produce perceptions of success through participation and positive sportsmanship behaviors [5]. For example, one study that fostered a task orientation focus within youth basketball practices found support that establishing a mastery motivational climate during practices may contribute to positive sportsmanship attitudes in players [25].

The surrounding social climate in youth sport is an important contextual consideration impacting whether competitive experiences result in positive or negative youth development outcomes and overall sportsmanship behaviors of players [8]. Early studies on competition provide examples of how altering the established purpose and management of youth sport programs can affect sportsmanship behaviors in either positive or negative directions [26]. More recent research continues to support the importance of social climate influences on sportsmanship. For example, not only does verbal communication from adults influence youth participants, but youth learn even more from their observations of adult behaviors [19]. Thus, coaches and parents need to evaluate how they view competition and their expectations for children playing competitive sport [19]. In addition, coaches may not realize the relevance of their role and the potential to impact the moral functioning and development of young athletes [27]. In one study, youth sport participants reported being more likely to engage in the unsportsmanlike behaviors of cheating and aggression during competitive sport if they perceived that the coach's norms would approve of the behavior [27]. Additionally, an additional study demonstrated that despite goal orientation, athletes highly valuing the need for social approval are more willing to consent to unsportsmanlike actions in order to benefit their performance [28]. Although there is existing 
research on the impact of sport social climate on sportsmanship, a better understanding is needed of how coaches, parents, and team members specifically impact the development of pro-social behaviors and sportsmanship [24].

\subsection{Competition in Youth Sport}

Another important consideration in understanding the context of youth sport is the role of competition. There is an ongoing controversy with both proponents and critics regarding the presence of competition in youth sport and perceptions of how competition may be influencing the development of participants. On one side of the controversy, there are those who promote competitive sport with the anecdotal assumption that participants will inevitably develop character and learn pro-social values such as sportsmanship, teamwork, and leadership [19]. On the other side of the argument, claims exist that all competition and sport specialization has a negative impact on the level of enjoyment, and sustained game participation [29]. There are those who believe competition and competitiveness may create risk factors to healthy development of youth participants [30], while others consider competition in and of itself to be damaging to positive values such as caring and cooperation [15].

A balance between attitudes suggests that competition is not by nature good or bad [19]. In addition, it may not be a question of cooperation versus competition but rather a question of how to best incorporate elements of cooperation within the structure of competitive youth sport [5]. In other words, competitive youth sport can contribute positively or negatively to sportsmanship and youth character development depending on how coaches, parents, and administrators design and implement to youth sport programs [19]. Therefore, a better question may be how and when should competitive activities be used and how can parents be an influence [31].

\subsection{Level of Competition and Sportsmanship}

Competition and sportsmanship are not mutually exclusive constructs and competitive environments can co-exist with the positive sportsmanship behaviors and overall moral development of players [19] [18]. However, the level of competition contributes an aspect to the game context that may influence the way that coaches, parents, and players perceive and act during games. Theoretically, the more intense the competition and the more perceived pressure to win, the more likely ego orientation will emerge during play which may negatively influence sportsmanship behaviors [19]. One study observed that as the level of competition increases in school basketball, coaches and players also increase in their emphasis on winning [32]. Increased pressure to have a winning team may result in negative coaching behaviors, neglect of players' personal development, and encouragement of unsportsmanlike conduct [4] [33] [34] [35]. When teams are competing at higher competitive levels, evidence has shown that coaches are more likely to provide players with feedback that is focused on performance outcomes as opposed to mastery outcomes [32]. This finding suggests that increasing levels of competition in youth sport may result in a shift from a mastery and skill development climate to a performance, ego-orientated climate.

More research is needed that considers competitive levels of sport participation as a potential component for foundational understanding of moral behavior in youth sport [8] as a connection may exist between competition level and sportsmanship behaviors [18]. Initial studies on the level of competition and presence of sportsmanship in youth sport suggest an inverse relationship between variables [36] [37] [24] [38]. However, little research exists that has directly examined whether level of competition influences variation in youth sportsmanship behaviors [6].

Furthermore, the research that does exist connecting sportsmanship and competition is somewhat limited in its definition of sportsmanship. Previous studies have tended to view sportsmanship as a single construct rather than recognizing the differences that exists between positive and negative sportsmanship behaviors. Positive sportsmanship behaviors in soccer may include helping an opponent up after a foul and kicking the ball out of bounds when there is an injury so the player can be attended to. Negative behaviors might include arguing with the referees and earning a red or yellow card for foul and abusive language or dissent. Simply refraining from negative behaviors does not necessarily mean an individual is engaging in positive ones and similarly, engaging in negative behaviors does not preclude engaging in positive behaviors as well. While it is becoming increasingly common to separate the two types of behaviors in research [39] [25], this needs to be done when discussing the impacts of competition level on behaviors. Therefore, the purpose of this study was to determine if differences in positive and negative sportsmanship behaviors exist at various levels of competitive youth sport experiences. Based on this purpose, the following two hypotheses will be tested:

$\mathrm{H}_{1}$ : Positive sportsmanship behaviors among players, coaches, and spectators will occur more frequently at a recreational level tournament than at an elite level tournament.

$\mathrm{H}_{2}$ : Negative sportsmanship behaviors among players, coaches, and spectators will occur less frequently at a recreational level tournament than at an elite level tournament.

\section{Methods}

\subsection{Setting}

This study took place at two different soccer tournaments in order to capture differences in competition level. The first location was at an elite competitive state tournament for travel soccer in the Mountain West region of the country. Teams had to qualify for the tournament and the winners were considered the state champions in that particular age group. In addition, the winners of the tournament went on to represent that state in the regional tournament leading up to the National Championship. A total of 62 games were 
observed at this tournament.

The second location was a less competitive tournament involving more recreational teams in the Southeast region of the country. Any team could register for this tournament and the most elite teams usually do not consider playing in the tournament as the perceived quality of play tends to be for those players less skilled. Teams were asked to rate their skill level and play in one of 3 color divisions. A tournament champion was then crowed in each color division for each age group. A total of 39 games were observed at this tournament.

\subsection{Participants}

Participants for this study included all players, coaches, and spectators present at games in the two locations described above. All the games observed involved male teams in two age groups: U-12 and U-14. These populations were selected based on the progression of moral development in adolescents. Youth in these age ranges are particularly vulnerable to the behaviors of others including peers, coaches, and other adults [40]. In particular, this is the age that children are beginning to seek greater independence and activities of peers and non parental adults can be more influential as they get older. Consequently, it seemed logical for the study to target these age groups.

\subsection{Measurement}

Systematic observation techniques were employed to assess both positive and negative sportsmanship behaviors. This technique has been successfully employed in studies of other youth sport experiences [39] [25] and similar observation tools were used in this study. The observation sheets were adapted by experts in soccer to reflect positive and negative sportsmanship behaviors that may be demonstrated in a youth soccer environment. Experts included both athletes and officials with several years of soccer experience. The resulting observation sheets included specific positive sportsmanship behaviors such as "participant shook opponents hand at the end of the game" and specific negative sportsmanship behaviors such as "participants made comments or gestures to demean or taunt an opponent".

Two observers were present at each game to quantify the exact number of times players, coaches, and spectators engaged in each of these behaviors. The use of two observers provided an insurance of consistency of recorded behaviors and in all cases the observer consistency was above $80 \%$ which was required as a threshold during the observer training as well. In addition, the observers were also asked to record anything that may have been out of the ordinary in terms of behaviors or comments that were heard to more fully support the research agenda and to provide as examples of behaviors or comments that were made.

\subsection{Observation Training}

Approximately one week before the study began at each location, the observers completed a training conducted by experts in sportsmanship and the use of systematic observation for data collection. These experts explained the background to the study and provided the observers with the observation sheets in order to discuss the positive and negative sportsmanship behaviors listed on the sheets and the ways in which those behaviors might be exhibited in youth soccer. After becoming familiar with the observation sheets, the observers viewed video clips of soccer games which demonstrated the behaviors in questions. Observers recorded which behaviors they saw and following the completion of the video segment, the expert and the observers discussed their perspectives on what was shown. This discussion took place until a consensus was reached on the behaviors that took place between the expert and all the observers. Then the video clip was viewed again in order to reinforce what was learned. In order to assess agreement among the observers, a goal was set that they would each attain a minimum $80 \%$ level of consistency. This level was met for both sets of observers. In the event that the $80 \%$ consistency was not reached, an additional video clip was shown, followed by discussion again to encourage the accurate recording of behaviors to achieve the desired level of agreement.

\section{Results}

\subsection{Descriptive Statistics}

Prior to conducting the hypothesis tests, researchers calculated means and standard deviations for each of the variables (positive sportsmanship and negative sportsmanship) at each level of competition (recreational and elite). These statistics can be seen in Table 1. Means for positive and negative sportsmanship per half game in the elite league were $9.774(\mathrm{sd}=7.303)$ and $9.226(\mathrm{sd}=7.822)$ respectively. In the recreational league, the mean for positive sportsmanship behaviors per half game was 9.513 (sd = 4.845), while the mean for negative sportsmanship behaviors per half game was $1.936(\mathrm{sd}=2.128)$.

\subsection{Hypothesis Tests}

The hypotheses were tested using a Multiple Analysis of Variance (MANOVA) in order to determine the impact of level of competition on positive and negative sportsmanship behaviors. Results of the analysis revealed no significant difference between level of competition on positive sportsmanship behaviors $\left(p=.780, \eta^{2}<.001\right)$ although the elite league's $(M=9.774, \mathrm{SD}=7.303)$ positive sportsmanship behaviors were slightly higher than the recreational league $(M=9.513, \mathrm{SD}=4.845)$. There was, however, a significant difference between recreational and elite leagues in negative sportsmanship behaviors $(p<.001$, $\left.\eta^{2}=.244\right)$ with the elite league $(M=9.226$, SD $=7.822)$ engaging in more negative sportsmanship behaviors per half than the recreational league $(M=1.936, \mathrm{SD}=2.128)$. Table 1 presents the results of this analysis which suggest that overall; the elite league tends to engage in poorer sportsmanship than the recreational league. 
Table 1. MANCOVA Results.

\begin{tabular}{lccllll}
\hline & $\boldsymbol{M}$ & SD & Mean Square & F & $\boldsymbol{p}$ & $\boldsymbol{\eta}^{2}$ \\
\hline Positive Sportsmanship & & & 3.271 & .078 & .780 & .002 \\
Elite League & 9.774 & 7.303 & & & \\
Recreational League & 9.513 & 4.845 & & & \\
Negative Sportsmanship & & & 2544.539 & 64.628 & & .001 \\
Elite League & 9.226 & 7.822 & & & \\
Recreational League & 1.936 & 2.128 & & & \\
\hline
\end{tabular}

\section{Discussion}

\subsection{Interpretation of Results}

This study was designed to more fully understand the relationship between sportsmanship behaviors (positive and negative) and competition level (recreational and elite) in a youth sport setting. Researchers predicted that positive sportsmanship behaviors would be higher in the recreational level youth sport games than in the elite level games. The data did not support this hypothesis. Positive behaviors, instead, were relatively similar between the two different tournaments. This may suggest that despite the higher levels of pressure on children in elite competition, positive behaviors have been engrained into the culture of the sport that they continue to engage in them no matter the circumstances. Simply put, it is understood that youth sport is designed to bring out positive behaviors in people and it seemed that in the case of both levels of competition, this was still the case. There may, however, be different reasons behind engaging in these behaviors. Each of the observers also provided comments/field notes throughout the game. Based on these, there may have been an interesting phenomenon regarding the engagement of positive sportsmanship behaviors. It appears that the overall "feel" for the recreational games was positive and players, parents and coaches all seemed to maintain this positivity out of respect for the game and the opponent's safety. This would appear to be consistent with previous research stating that a good predictor of player behavior is the likelihood that others are acting the same way. In other words, in the recreational games players witnessed very positive behaviors in many situations and as a result, reacted similarly because that was how others were behaving.

Conversely, the elite, state championship games appeared to have positive behaviors as a result of a better understanding for the rules of the game (participant played the ball out of play for injuries) as well as the level of familiarity the opponents had for one another (many of these teams had played each other numerous times throughout the season or played on school teams together but not the club level teams etc.). This is consistent with much of the prosocial behavior literature which suggests that opponents are more likely to respect one another if they have a degree of familiarity with each other through previous interactions or conversations [41].

Negative sportsmanship behaviors within each of these environments present a much different story. A significant difference did exist in negative sportsmanship behaviors based on competitive environment with the elite young athletes engaging in higher levels of negative behaviors than the recreational young athletes as predicted by the hypothesis. In fact, the young athletes in the elite tournament engaged in approximately four times the number of negative sportsmanship behaviors per half game as the young athletes in the recreational tournament. Perhaps, this is where the increased levels of pressure due to increased competitive level are manifested. Some would argue that while there were more negative behaviors in the elite game, there were more opportunities for behaviors simply because the game moves faster and there is a greater likelihood for behaviors to occur. The authors would agree that this might be a viable argument, however, if this was the case, why were there not more positive behaviors displayed as well? Clearly something else is happening in this competitive environment beyond simply a faster game. Players at this level are certainly more skilled or they would not be participating at such a level which also means they have are likely being coached more intensely. Many coaches attempt to teach not only the skills of the game but the tactics as well and unfortunately, many of the players do not fully understand how to properly implement the tactics and, as such, are perceived as negative such as taunting an opponent.

In addition, many of the games at the state championship tournament were single elimination and, therefore, the pressure to perform may have been heightened. Parents, coaches and players recognize this and a simple decision from a referee that could have a large impact on the game may be met with emotional outburst and negative behaviors. Teams recognize that individual actions or decisions are magnified because of the elimination nature of the game and this often leads to more outbursts of negative emotion.

\subsection{Limitations and Implications for Future Research}

The results provided in this study take the first step in understanding the relationship between level of competition and sportsmanship behaviors. Limitations do exist, however, which may impact the generalization of results. To begin, only one sport was studied. It may very well be the case that athletes in other sports respond differently to the type of competitive environment. Consequently, it would be beneficial to study these relationships in other sports. While doing so, it is also important to keep in mind that soccer is a team sport. The environments of team versus individual sports are very different and the literature supports the notion 
that team sport situations tend to be less positive in their approach toward the rules, the game and their opponents. In fact, previous research has shown that athletes in team sports show significantly less concern for their opponents than athletes in individual sports [42]. Therefore, athletes in team versus individual sports may also have differences in sportsmanship behaviors and when researching sportsmanship behaviors in connection to competitive environment it is necessary to ensure that all types of sporting environments are understood.

Another limitation to the study that can be improved upon in future research was that it observed games with only male athletes. This was necessary for logistical reasons but it may limit the application of results to environments involving female or co-ed teams. Previous sportsmanship research has demonstrated a difference between males and females in several aspects of sportsmanship behavior [24]. This is likely because of the different goals and outcomes that males and females seek to achieve a game environment. For example, females tend to rate socialization more highly than males in describing why they participate in a sport setting while males tend to cite transition into adulthood more frequently [43]. Future researchers could expand the study to determine if differences in sportsmanship behaviors based on competition level are similar or different with other types of teams.

The age range of the young athletes in this study is another potential limitation. Games were only observed where the players were in two age groups: U-12 and U-14. While this was an appropriate age range to study based on developmental patterns [40], the results from this study should not be generalized to other age groups. It may very well be that older or younger children in elite and recreational leagues react much differently in terms of positive and negative sportsmanship, and, consequently, it would be beneficial for future studies to broaden the range of observations to include these groups or to study them individually.

Finally, the study was limited by its relatively small sample size. Only 101 games were observed (for a total of 202 half games) in only two locations. A larger study completed over a broader spectrum of the country might further add to the understanding of positive and negative sportsmanship behaviors in competitive youth sport environments.

In addition to addressing the limitations of this particular study, future research may look at a variety of other areas to more deeply understand this issue. To begin, it would be interesting to separate and compare the behaviors of the players, coaches, and parents in these environments to determine if there are differences in how each of these groups behaves in these two competitive environments. Other researchers may focus on comparing age groups or may look more specifically at the exact behaviors in which individuals are engaging. This could assist youth sport professionals in targeting specific behaviors to enhance the levels of sportsmanship in games, and improving the overall experience for all involved. Still more researchers may be more focused on the methods of sportsmanship observation.
It might be possible to improve data collection procedures, perhaps through the use of technology, to collect and enter data.

\subsection{Implications for Practice}

In addition to future research ideas, the results from this study also provide several implications for practice. To begin, although it is often easy to overlook in an environment where negative behaviors frequently get featured in the media and through word-of-mouth, positive sportsmanship behaviors do dominate negative ones in youth sport. Positive sportsmanship behaviors were high in both levels of competition and in both were also higher than negative sportsmanship behaviors. This is crucial information for youth sport professionals for two reasons. First, it is important to maintain these levels. While it is easy to look at what is wrong and attempt to fix it, a focus should also be on maintaining or maximizing the good. It would behoove youth sport professionals to try and ascertain what elements of their programs are promoting these positive behaviors and strengthen them when possible to further enhance the environments in which their young athletes are playing. Second, youth sport professionals should also focus on promoting the good elements of their sporting environments. Far too often in any culture or environment, the news that spreads is what is going wrong. Unfortunately, drawing attention to a problem can sometimes exacerbate it for a variety of reasons. For example, some individuals may continue the behavior out of a need for attention or some individuals may withdraw from what is seen as a negative program, leaving a higher concentration of problems among those who are left. Promoting the positive aspects of the program creates an environment where those individuals seeking attention can be recognized more for doing good than for doing bad, and also creates a better overall reputation among the program. Youth sport professionals may look toward sportsmanship awards in games or tournaments for both teams and individuals to promote such behaviors. For further promotion, these programs could include write-ups on teams or individual athletes in weekly or monthly newsletters describing exactly the behaviors they are being recognized for in order to promote those behaviors to others.

Similarly, since positive behaviors are so prominent, even in the most competitive of game situations, rules need not be put in place to eliminate or minimize these positive behaviors. For example, many leagues will suggest that a coach or player may not approach an official after a match for fear of the negative behaviors that may be displayed when in fact what is happening is they are preventing the positive behaviors from taking place. More often than not, a coach and/or player act appropriately toward officials after a game and shake their hands with respect and dignity, however, in the few instance in the season when someone perhaps says something he or she should not, leagues seek ways to eliminate the bad behavior without thinking through all the good behaviors that came before. Leagues should determine 
ways to eliminate these negative behaviors without compromising the positive examples being set by all the other players and coaches who behave appropriately and respectfully by shaking hands after a game.

When it comes to negative sportsmanship behaviors, the results of this study imply that heightened levels of competition lead to young athletes engaging in more negative behaviors. Although the goal of all youth sports professionals should be to eliminate any negative sportsmanship behaviors, the results from this study that, while not perfect, lower levels of competitive environments are performing reasonably well in this area. Consequently, a much greater focus needs to be upon the elite levels of competition. Youth sport professionals working with athletes in higher levels of competition need to not only be aware that this is an issue, but should also develop strategies for how to resolve it. Since coaches are such a large influence at this level, additional coaches trainings may be useful based on the understanding that players will act in accordance with the culture of the team that is determined largely by the coach [42] [44].

Another potential implication from these results is for the parents of young athletes. Frequently prior to participation, parents cite reasons for enrolling their children in youth sport such as building friendships, learning teamwork, and learning good sportsmanship. If parents are truly concerned about these ideals, perhaps their children should participate in leagues with less pressured environments to maximize the positive messages and benefits the children can hear and gain in a sports environment. With fewer than $2 \%$ of high school athletes getting full college scholarships, it actually would be more beneficial for parents to spend all the money they spend on the competitive traveling teams on an educational tutor and enroll their children in the recreational leagues in their communities. It is cheaper, more positive, and children are more likely to obtain an academic scholarship than an athletic one anyway.

Finally, youth sport professionals in recreational leagues could use this information to their advantage when marketing their programs to increase participation rates. It may be very beneficial for leagues in the recreational competition level to promote the idea that their leagues promote better sportsmanship in order to increase their share of the market of players whose parents are seeking for their children to "build character".

\section{Conclusion}

This article demonstrates that differences do, in fact, exist between the competitive nature of different environments and the demonstration of sportsmanship in youth soccer. Based on this knowledge, youth sport professionals can better design programs to service their participants, thereby, enhancing the experiences they have as young athletes. While this is likely to benefit the organization and administrators, the greater benefit, perhaps, lies in the future of the children involved as these greater experiences should lead to more positive youth development and help them to maintain participation in sport.

\section{References}

[1] Bouchard, C., Shepard, R. J., and Stephens, T. (Eds.) 1994. Physical activity, fitness, and health. Champaign, IL: Human Kinetics.

[2] Danish, S. J., Petitpas, A. J., and Hale, B. D. 1990. Sport as a context for developing competence. In T. Gullotta, G. Adams, and R. Monteymar (Eds.), Developing social competency in adolescence (Vol. 3, pp. 169-194). Newbury Park, CA: Sage.

[3] Metzl, J. D. 2002. The young athlete. Boston: Little Brown.

[4] Hansen, D. M., Larson, R. W., and Dworkin, J. B. 2003. What adolescents learn in organized youth activities: A survey of self-reported development experiences. Journal of Research on Adolescence, 13 (1), 25-55.

[5] Daniels, A. M. 2007. Cooperation versus competition: Is there really such an issue? In D. F. Perkins and S. Le Menestral (Eds.), New directions for youth development: Sports-based youth development (pp. 43-56). Washington D. C.: JosseyBass.

[6] Le Menestral, S., and Perkins, D. F. 2007. An overview of how sports, out-of-school time, and youth well-being can and do intersect. In D. F. Perkins and S. Le Menestral (Eds.), New directions for youth development: Sportsbased youth development (pp. 13-25). Washington D. C.: Jossey-Bass.

[7] Thornton, C. M., Cain, K. L., Conway, T. L., Kerr, J., Saelens, B. E., Frank, L. D., Glanz, K., and Sallis, J. F. 2017. Relation of adolesents' physical activity to after-school recreation environment. Journal of Physical Activity and Health, 14 (5), 382-388.

[8] Baron, L. J. 2007. Contemporary issues in youth sports. New York: Nova Science Publishers.

[9] Bergeron, M. F. 2007. Improving health through youth sports: Is participation enough? New Directions for Youth Development, 115, 27-41.

[10] Centers for Disease Control and Prevention (CDCP). 2015. Physical activity and health: A report of the surgeon general. Atlanta, GA: U.S. Department of Health and Human Services.

[11] Coakley, J. 2016. Sports in society: Issues and controversies (12 ${ }^{\text {th }}$ ed.). New York: McGraw Hill.

[12] Ewing, M. E., Gano-Overway, L. A., Branta, C. F., and Seefeldt, V. D. 2002. The role of sports in youth development. In M. Gatz, M. A. Messner, and S. J. Ball-Rokeach (Eds.), Paradoxes of youth sport (pp. 31-47). Albany, NY: State University of New York Press.

[13] Shields, D. L. L., and Bredemeier, B. J. L. 1995. Character development and physical activity. Champaign, IL: Human Kinetics.

[14] Hellison, D. 2011. Teaching social and personal responsibility through physical activity. ( $3^{\text {rd }}$ ed.) Champaign, IL: Human Kinetics.

[15] Fullinwider, R. K. 2006. Sports, youth and character: A critical survey. College Park, MD: Center for Information and Research on Civic Learning and Engagement, University of Maryland. 
[16] Holt, N. L. 2016. Positive Youth Development Through Sport. $\left(2^{\text {nd }}\right.$ ed.) Routledge, New York, NY.

[17] Stevenson, C. L. 1975. Socialization effects of participation in sport: A critical review of the research. Research Quarterly, 46, 297.

[18] Goldstein, J. D., and Iso-Ahola, S. E. 2006. Sportsmanship in youth sports. The Journal of Physical Education, Recreation, \& Dance, 77 (7), 18-24.

[19] Murphy, S. 1999. The cheers and the tears: A healthy alternative to the dark side of youth sports today. San Francisco, CA: Jossey-Bass Publishers.

[20] Corrion, K., Long, T., Smith, A. L., and d'Arripe-Longueville, F. 2009. "It's not my fault; It's not serious": Athletic accounts of moral disengagement in competitive sport. The Sport Psychologist, 23, 388-404.

[21] Dorsch, T. E., Smith, A. L., Dotterer, A. M. 2016. Individual, relationship, and context factors associated with parent support and pressure in organized youth sport. Psychology of Sport and Exercise, 23, pp. 132-141.

[22] Perkins, D. F., and Noam, G. G. 2007. Characteristics of sports-based youth development programs. New Directions for Youth Development, 115, 75-84.

[23] Duda, J. L. 1993. Goals: A social-cognitive approach to the study of achievement motivation in sport. In R. N. Singer, M. Murphy, and L. K. Tennant (Eds.), Handbook of research on sport psychology (pp. 421-436). New York: MacMillan.

[24] Ryska, T. A. 2003. Sportsmanship in young athletes: The role of competitiveness, motivational orientation, and perceived purpose of sport. The Journal of Psychology, 137 (3), 273293.

[25] Wells, M. S., Ellis, G. D., Arthur-Banning, S. G., and Roark, M. 2006. Effects of staged practices and motivational climate on goal orientation and sportsmanship in community youth sport experiences. Journal of Parks and Recreation Administration, 24 (4), 64-85.

[26] Sherif, M., and Sherif, C. 1969. Social Psychology. New York: Harper and Row.

[27] Guivernau, M., and Duda, J. L. 2002. Moral atmosphere and athletic aggressive tendencies in young soccer players. Journal of Moral Education, 31 (1), 67-85.

[28] Bolter, N. D. and Weiss, M. R. 2016. Routledge International Handbook of Sport Psychology: Delivering on the Promise. Routledge, New York.

[29] Chalip, L. and Hutchinson, R. 2017. Reinventing youth sport: formative findings from a state-level action research project. Sport in Society, 20 (1), 30-46.

[30] David, P. 2005. Human rights in youth sports: A critical review of children's rights in competitive sports. New York: Routledge.
[31] Pynn, S. R., and Holt, N. L. 2017. Toward a conceptualization of good parenting in youth sport. Journal of Exercise, Movement, and Sport, 49 (1), 68-78.

[32] Chaumeton, N. R., and Duda, J. L. 1988. Is it how you play the game or whether you win or lose? The effect of competititve level and situation on coaching behaviors. Journal of Sport Behavior, 11, 157-174.

[33] Smith, N., Quested, E., Appleton, P. R. and Duda, J. L. 2017. Observing the coach-created motivational environment across training and competition in youth sport. Journal of Sports Sciences, 35 (2), 149-158.

[34] Roberts, G. C., and Treasure, D. C. 1992. Children in sport. Sport Science Review, 1, 46-64.

[35] Smoll, F., and Smith, R. 1989. Leadership behaviors in sport: A theoretical model and research paradigm. Journal of Applied Social Psychology, 19, 1522-1551.

[36] Bredemeier, B. J. 1995. Divergence in children's moral reasoning about issues in daily life and sport. International Journal of Sport Psychology, 26, 453-464.

[37] Carpenter, P. J., and Yates, B. 1997. Relationship between achievement goals and the perceived purposes of soccer for semiprofessional and amateur players, Journal of Sport \& Exercise Psychology, 19, 302-311.

[38] White, S. A. 1995. The perceived purposes of sport among male and female intercollegiate and recreational sport participants. International Journal of Sport Psychology, 26, 490-502.

[39] Arthur-Banning, S. G., Paisley, K., and Wells, M. S. 2007. Promoting sportsmanship in youth basketball players: The effects of referees' prosocial behavior techniques. Journal of Park and Recreation Administration, 25 (1), 96-114.

[40] Brown, B. B., Bakken, J. P., Ameringer, S. W., and Mahon, S. D. 2008. Understanding peer influence in children and adolescents. New York: Guiliford Press.

[41] Ellis, G. D., Paisley, K. P., Wells, M. S., Silverberg, K., and Henderson, H. 2004. How to Promote Sportsmanship in Your Youth Sport Leagues: The Play Hard, Play Fair, Play Fun Program. Parks and Recreation, 39 (6), 46-51.

[42] Vallerand, R. J., Deshaies, P., and Cuerrier, J. P. 1997. On the effects of the social context on behavioural intentions of sportsmanship. International Journal of Sport Psychology, 28 (2), 126-140.

[43] Coakley, J. and White, A. 1992. Making decisions: Gender and sport participation among British adolescents. Sociology of Sport Journal, 9, 20-35.

[44] Wells, M. S., Arthur-Banning, S. G., Paisley, K. P., Ellis, G. D., Roark, M. F., and Fisher, K. 2008. Good (Youth) Sports: Using Benefits-based Programming to Increase Sportsmanship. Journal of Park and Recreation Administration, 26 (1), 1-21. 